\title{
Ongoing outbreak with well over 4,000 measles cases in Italy from January to end August 2017 - what is making elimination so difficult?
}

A Filia ${ }^{12}$, A Bella ${ }^{12}$, M Del Manso $^{1}$, M Baggieri $^{3}$, F Magurano $^{3}$, MC Rota $^{1}$

1. Department of Infectious Diseases, Istituto Superiore di Sanità, Rome, Italy

2. These authors contributed equally to this article and share first authorship

3. National Reference Laboratory for Measles and Rubella, Istituto Superiore di Sanità, Rome, Italy

Correspondence: Antonietta Filia (antonietta.filia@iss.it)

Filia A, Bella A, Del Manso M, Baggieri M, Magurano F, Rota MC. Ongoing outbreak with well over 4,00o measles cases in Italy from January to end August $2017-$ what is making elimination so difficult?. Euro Surveill. 2017;22(37):pii=30614. DOI: http://dx.doi.org/10.2807/1560-7917.ES.2017.22.37.30614

Article submitted on 06 September 2017 / accepted on 14 September 2017 / published on 14 September 2017

We report an ongoing measles outbreak in Italy, with over 4,400 cases reported in 20 Regions from January to August 2017. Median age was 27 years, $88 \%$ of the cases were unvaccinated. The highest incidence was in infants below one year of age and $7 \%$ of cases occurred among healthcare workers. Three deaths occurred and two cases of encephalitis were reported. Wide immunity gaps and nosocomial transmission are major challenges to measles elimination in Italy.

Measles is targeted for elimination in Italy as in the World Health Organization (WHO) European Region, however, Italy remains one of the 14 countries in the Region with ongoing endemic transmission [1]. In January 2017, the Italian National Health Institute (Istituto Superiore di Sanità-ISS) detected an increase in the number of measles cases reported to the national measles and rubella integrated surveillance system, compared with previous months and years.

We describe characteristics of cases reported in the first 8 months of 2017, main transmission settings, and control measures implemented.

\section{Outbreak description}

Between 1 January and 31 August 2017, 4,477 cases were reported to the surveillance system, of which $3,417(76.3 \%)$ were laboratory confirmed $(3,189$ in WHO-accredited laboratories), 456 (10.2\%) were probable and 604 (13.5\%) were possible cases according to the European Union (EU) case definition [2]. Figure 1 shows the distribution of measles cases by month of rash onset from January 2013. The peak number of reported cases was reached in March 2017, with 900 cases reported. The outbreak is ongoing at the time of writing this article.
The current outbreak affected 20 of the 21 Italian administrative regions but 4,015 (90\%) of the cases were reported by only seven regions. The Lazio region, in central Italy, reported the highest number of cases $(n=1,588)$ and the highest incidence $(269.7 / 1,000,000$ population) (Figure 2).

Median age was 27 years (range 25 days -84 years) and $2,270(50.7 \%)$ of the cases were female. Most cases $(n=3,301 ; 73.8 \%)$ were above 15 years of age, but the highest incidence occurred in children aged under one year (Table 1).

Vaccination status was known for $93.4 \%$ of cases $(n=4,182)$, of whom $88.3 \%(n=3,691)$ were unvaccinated, $6.5 \%(n=271)$ had received only one dose of measles-containing vaccine, $1.6 \%(n=69)$ were fully vaccinated and $3.6 \%(n=151)$ had received an unknown number of doses.

The probable transmission setting is known for $30.2 \%$ $(n=1,352)$ of the cases. Transmission occurred in families $(64.1 \% ; n=867)$, nosocomial settings $(22.3 \%$; $n=301)$, schools $(10.1 \% ; n=137)$ and nomadic settlements $(3.5 \% ; n=47)$.

Two hundred ninety-six cases (6.6\%) occurred among healthcare workers (HCWs), defined as any hospital or other healthcare staff having regular contact with patients. Cases among HCWs were reported from 16 Regions. Median age was 33 years (range: $19-57$ years). Vaccination status of HCWs was reported in $94.9 \%$ of cases $(n=281): 239(85.1 \%)$ were not vaccinated, 28 $(10.0 \%)$ had received one dose, $8(2.8 \%)$ two doses, 6 $(2.1 \%)$ could not recall the number of doses received.

Genotypes B3, D8 and $\mathrm{H}_{1}$ were identified: $\mathrm{B} 3$ and D8 represent endemic genotypes, while genotype $\mathrm{H}_{1}$ was 
Reported measles cases by month of rash onset, Italy, January 2013-August $2017(n=9,559)$

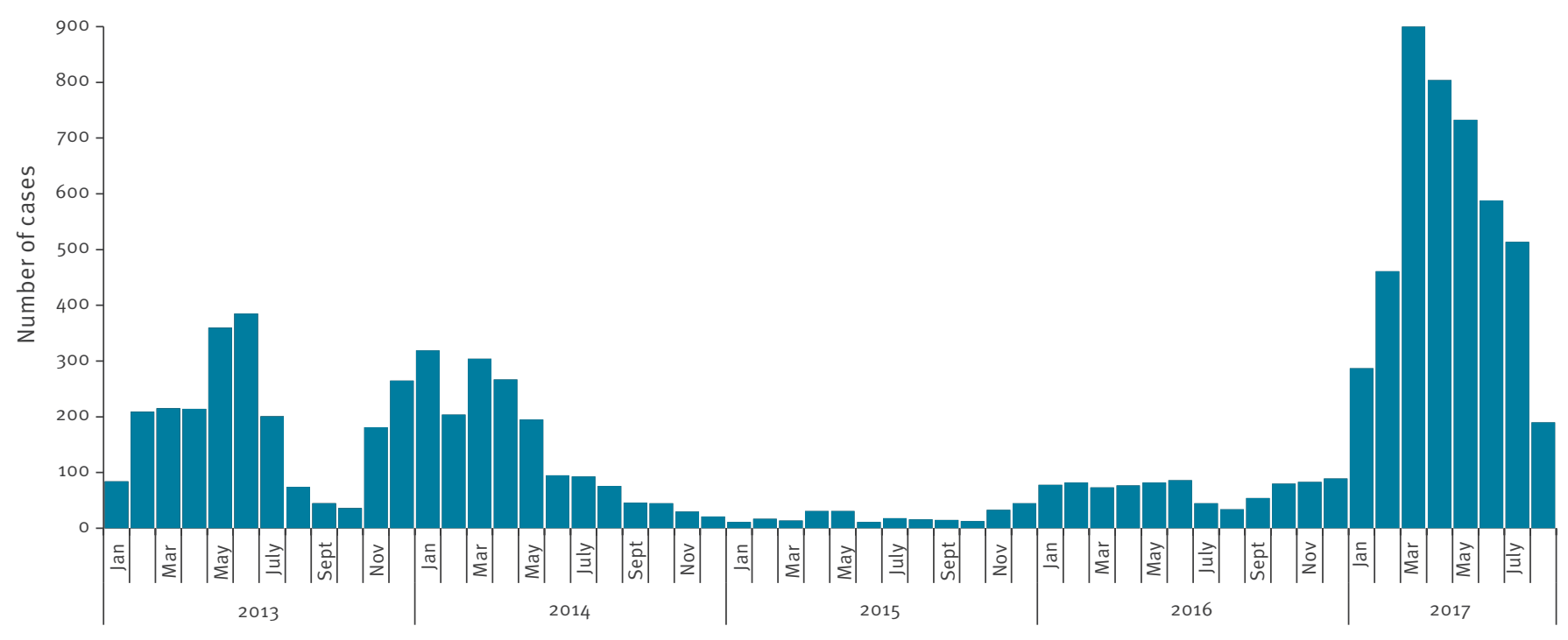

identified only in one small outbreak at the beginning of the year.

Complications were reported by $35.1 \%(n=1,571)$ of cases. Diarrhoea was the most frequent complication (16.0\%; $n=717$ cases) followed by stomatitis (13.9\%; $\mathrm{n}=622)$, keratoconjunctivitis (9.3\%; $n=418)$, hepatitis (8.7\%; $n=391)$, pneumonia $(7.8 \% ; n=349)$, respiratory insufficiency $(6.3 \% ; n=282)$, otitis media $(4.6 \% ; n=206)$, thrombocytopenia ( $3.2 \% ; n=143)$, seizures $(0.2 \% ; n=11)$, and other complications $(2.9 \%$; $\mathrm{n}=129)$. The highest frequency of complications $(38.5 \% ; n=1,180)$ was seen in the age group over 20 years (Table 2 ).

Two cases of encephalitis were reported, one in a 37-year-old adult, and the other in a one-year-old child. Three deaths due to respiratory insufficiency occurred among children aged 16 months, 6 years and 9 years respectively. All were unvaccinated and one child was immunocompromised due to ongoing chemotherapy for a malignancy. Measles was laboratory confirmed in all three children.

Overall, $43.2 \%(n=1,933)$ of cases were hospitalised and an additional $22.4 \%(n=1,005)$ consulted an emergency department.

\section{Public health measures}

In January, national authorities immediately informed all regional coordinators of the increased number of cases being reported, asking them to intensify surveillance and investigation of outbreaks. They issued two circulars; the first one was intended to remind all regional and local health authorities of the control measures recommended by the national measles elimination plan (including informing family physicians, paediatricians, gynaecologists, hospital and emergency-room physicians of the outbreak, vaccinating susceptible contacts from 6 months of age, administering immunoglobulins to susceptible contacts at high risk of complications, such as pregnant women, immunocompromised subjects and infants below 6 months of age, implementing supplementary vaccination activities, putting in place isolation protocols and infection-control measures, and distributing communication materials for HCWs and the population), while the second gave more specific recommendations regarding the administration of immunoglobulins $[3,4]$.

Some regional health authorities released their own specific guidelines which included: (i) for general practitioners and paediatricians, the recommendation to limit referral of cases to hospitals only to those cases presenting symptoms or signs of a measles complication, in order to prevent nosocomial transmission; (ii) for hospitals, verifying the immunity status of all HCWs and vaccinating susceptible HCWs.

ISS publishes a monthly measles report and the frequency was increased to weekly bulletins to provide timely information about the measles situation in the Regions. These were published on the websites of the Ministry of Health and the ISS (EpiCentro portal), in both Italian and English languages [5,6].

The United States (US) Centers for Disease Control and Prevention (CDC) in Atlanta issued a warning for travellers to Italy on 17 April 2017 [7]. CDC recommended that travellers to Italy make sure they are protected against measles. More specifically, they recommended one dose of measles vaccine for infants aged 6-11 months and two doses for children aged 1 year or older. 


\section{FIGURE 2}

Incidence per 1,000,000 population of reported measles cases by Region, Italy, January-August 2017

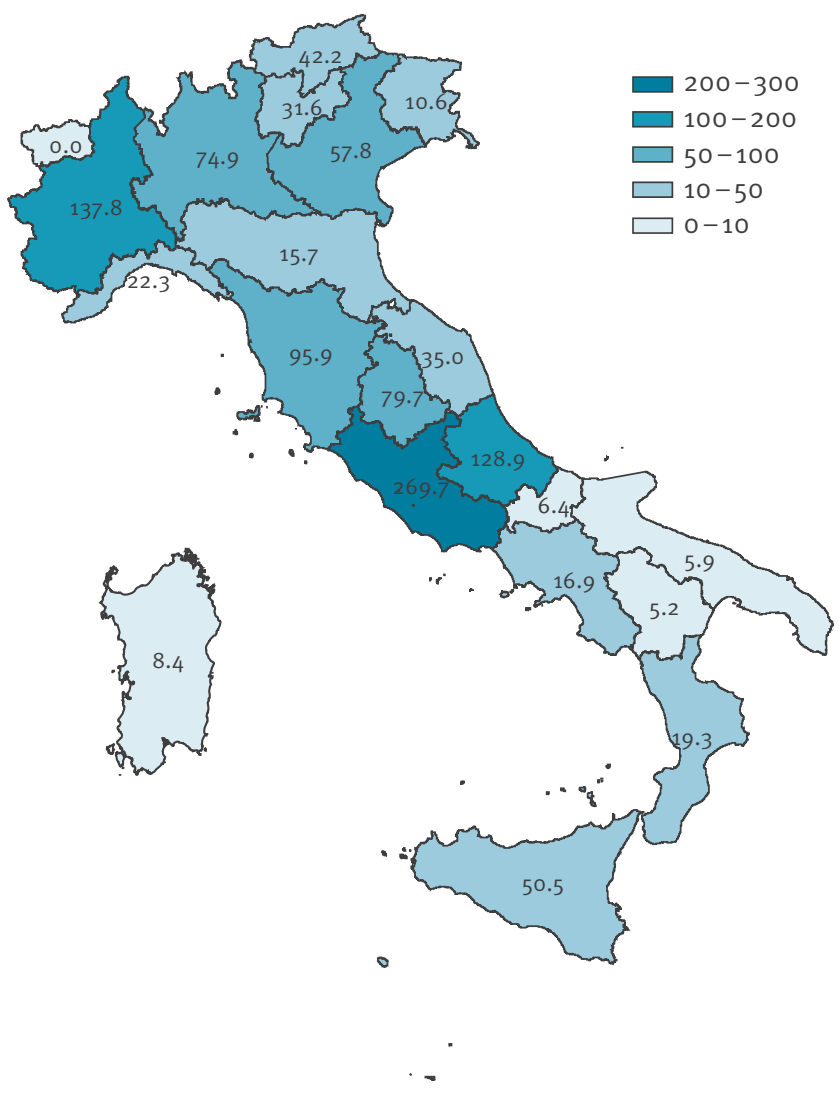

\section{Discussion}

The main reason for this outbreak is an accumulation of a large pool of measles-susceptible population due to sustained low uptake of measles vaccine in Italy over the years. Measles vaccine uptake was very low in the years following its introduction in Italy in 1976 and this has led to large vaccination gaps among adolescents and young adults, and a constantly increasing median age of reported cases [8]. The national measles elimination plan of 2011 called for supplementary immunisation activities among children over 2 years of age and susceptible groups, but these have been scarcely implemented.

Although vaccine uptake for the first dose improved after implementation of the first national elimination plan in 2003, reaching $90.6 \%$ in 2010 , the target of $95 \%$ was never reached. Uptake remained stable at around $90 \%$ until 2013 but since then has decreased to $85.3 \%$ in 2015 , leading to a further increase in the pool of susceptible children below four years of age, the age group with the highest incidence in the current outbreak [9]. Second-dose coverage at 6 years of age is also currently below $90 \%$ [9].

Decreased uptake of measles-mumps-rubella (MMR) vaccine in Italy in recent years is the result of vaccine hesitancy [10]. In July 2017, the Italian government
TABLE 1

Number and incidence per 1,000,000 age-specific population of reported measles cases, by age group, Italy, January-August 2017

\begin{tabular}{|l|c|c|c|}
\hline $\begin{array}{l}\text { Age group } \\
\text { (years) }\end{array}$ & Number & Percentage & $\begin{array}{c}\text { Incidence } \\
\text { (per 1,000,000 population) }\end{array}$ \\
\hline$<1$ & 253 & 5.7 & 541.0 \\
\hline $1-4$ & 543 & 12.1 & 267.0 \\
\hline $5-14$ & 378 & 8.4 & 66.5 \\
\hline $15-39$ & 2,525 & 56.4 & 152.7 \\
\hline$>39$ & 776 & 17.3 & 21.6 \\
\hline Total & $\mathbf{4 , 4 7 5 ^ { \mathrm { a } }}$ & $\mathbf{1 0 0 . 0}$ & $\mathbf{7 3 . 9}$ \\
\hline
\end{tabular}

a Information on age was not available for two cases.

approved a law [11] extending the number of mandatory vaccinations in persons up to 16 years of age. As of September 2017, proof of vaccination against 10 vaccine-preventable diseases or of having booked appointments with the local vaccination service to receive any missing vaccinations by 10 March 2018, will be required to attend kindergarten and nurseries. Older children attending elementary or middle school will also be required to present proof of vaccination; lack of compliance will not limit their access to school, but parents refusing vaccination will be required to undergo an interview by the local health authorities and to explain their reasons for not vaccinating. Following the interview, financial sanctions will be applied to families who continue to refuse to vaccinate their children.

In 2016-17, measles outbreaks have also been reported in other European countries [12]. Romania reported over 7,000 cases and 31 deaths from January 2016 to June 2017, most of them in small children [12]. On the contrary, in Italy over $70 \%$ of cases were among adolescents and young adults. The age differences in the two countries may be explained by the different levels of vaccine uptake after vaccine introduction. Currently, uptake is comparable in the two countries; however, contrary to Italy, Romania had very high vaccine uptake (>95\%) up to 2010 so many adults are protected [13].

Among the young adults affected in the current measles outbreak there are a large number of healthcare workers, and, as in previous outbreaks in Italy, nosocomial transmission was an important transmission setting [14-16]. In Italy, MMR vaccine is not required for employment as a HCW. Besides improving vaccination uptake among HCWs, there is an urgent need for implementing isolation protocols and infection control guidelines in all healthcare waiting rooms [14]. Maintaining a high index of suspicion of measles in patients with rash illness is also crucial $[14,15]$.

The percentage of hospitalised cases in this outbreak is very high, as was the case in Wallonia, Belgium [17]; 
Number and percentage of complicated cases and hospitalisations by age group, measles outbreak, Italy, January-August 2017

\begin{tabular}{|c|c|c|c|c|c|c|c|}
\hline \multirow{2}{*}{ Age group } & \multirow{2}{*}{ Number of cases } & \multicolumn{2}{|c|}{$\begin{array}{c}\text { Complicated cases } \\
\text { (at least one complication) }\end{array}$} & \multicolumn{2}{|c|}{$\begin{array}{c}\text { Cases with more than one } \\
\text { complication }\end{array}$} & \multicolumn{2}{|c|}{ Cases hospitalised } \\
\hline & & $n$ & $\%$ & $\mathrm{n}$ & $\%$ & $\mathrm{n}$ & $\%$ \\
\hline <1 year & 253 & 63 & 24.9 & 34 & 13.4 & 140 & $55 \cdot 3$ \\
\hline $1-4$ years & 543 & 159 & 29.3 & 87 & 16.0 & 246 & $45 \cdot 3$ \\
\hline 5-19 years & 614 & 169 & 27.5 & 78 & 12.7 & 201 & 32.7 \\
\hline$>20$ & 3,065 & 1,180 & 38.5 & 726 & 23.7 & 1,345 & 43.9 \\
\hline Total & $4,475^{a}$ & 1,571 & 35.1 & 925 & 20.7 & $1,932^{b}$ & 43.2 \\
\hline
\end{tabular}

a Information on age was not available for two complicated cases.

b Information on age was not available for one hospitalised case.

this may be due to some degree of under-reporting of milder cases who either did not seek medical care or who were not reported by primary care physicians. Also, the transmission setting was known for only one third of cases reported so the percentage of infections transmitted in hospitals may be even higher than indicated and other transmission settings (such as workplaces, public gatherings) may not have been identified. Contrary to other measles outbreaks reported in Italy in recent years and more recently in other European countries $[18,19]$, the Roma/Sinti population was not particularly affected in this outbreak. Only 47 cases reported, $1 \%$ of the total, belonged to this group.

In addition to illness and death caused by the disease, measles outbreaks require considerable healthcare resources for evaluating cases and implementing control measures. Furthermore, the health warning by the US CDC highlights possible implications of such outbreaks beyond the immediate public health concerns in a specific country or region.

In conclusion, the size of the described outbreak highlights that there are wide measles immunity gaps in the Italian population, which together with nosocomial transmission are challenges to elimination. The new vaccination law in Italy will hopefully close immunity gaps in persons up to 16 years of age but further efforts will be necessary to reach other susceptible groups, including young adults and HCWs, through countryspecific tailored strategies, and to further strengthen surveillance and outbreak response [20].

\section{Acknowledgements}

The authors wish to thank staff in regional and local health authorities involved in outbreak investigation and reporting of measles cases to the national surveillance system.

\section{Conflict of interest}

None declared.

\section{Authors' contributions}

AF coordinates the national measles and rubella integrated surveillance system, interpreted the data and wrote the manuscript. $A B$ manages the web-based platform for data collection and analysed the data. MDM contributed to data management and analysis. MB and FM provided laboratory and genotype data from the national reference laboratory for measles surveillance. MCR interpreted the data and critically revised the manuscript. All authors reviewed and approved the final manuscript.

\section{References}

1. World Health Organization Regional Office for Europe (WHO/ Europe). Fifth Meeting of the European Regional Verification Commission for Measles and Rubella Elimination (RVC) 24-26 October 2016, Copenhagen, Denmark. Copenhagen: WHO/ Europe; [Accessed 31 Aug 2017]. Available from: http://www. euro.who.int/_data/assets/pdf_file/0005/330917/5th-RVCmeeting-report.pdf?ua $=1$

2. European Commission. Commission Implementing Decision of 8 August 2012 amending Decision 2002/253/EC laying down case definitions for reporting communicable diseases to the Community network under Decision No 2119/98/EC of the European Parliament and of the Council. Luxembourg: Publications Office of the European Union. L262 Sep 27, 2012. Available from: http://eur-lex.europa.eu/legal-content/EN/TXT / ? uri=0J\%3AL\%3A2012\%3A262\%3ATOC

3. Italian Ministry of Health $(\mathrm{MoH})$. Situazione epidemiologica del morbillo - Indicazioni operative per la gestione dell'epidemia in atto. [Circular N. 10740 of 4 April 2017. Recommendations for control of the ongoing measles outbreak]. Rome: $\mathrm{MoH}$; [Accessed 31 Aug 2017]. Italian. Available from: http://www. trovanorme.salute.gov.it/norme/renderNormsanPdf?anno=201 $7 \&$ codLeg $=58889 \&$ parte $=1 \% 20 \&$ serie $=$ null

4. Italian Ministry of Health $(\mathrm{MoH})$. Morbillo. Chiarimenti sulla somministrazione di immunoglobuline e sulla prima dose di MPR in particolari condizioni. [Circular N. 19361 of 23 June 2017. Measles: Clarifications regarding the administration of immunoglobulins and the first MMR dose in specific situations]. Rome: MoH; [Accessed 31 Aug 2017]. Italian. Available from: http://www.trovanorme.salute.gov.it/norme/ renderNormsanPdf;jsessionid $=-\mathrm{CkvBp}-+\mathrm{DKv}-\mathrm{MU}+\mathrm{socO}$ zg__.sgc4-prd-sal?anno $=2017 \&$ codLeg $=59751 \&$ parte $=1 \% 20$ \&serie=null

5. Istituto Superiore di Sanità (ISS). EpiCentro portal. Morbillo in Italia: Bollettino settimanale. [Measles in Italy: weekly bulletin]. Rome: ISS; 5 Sep 2017. Italian. Available from: http:// www.epicentro.iss.it/problemi/morbillo/Infografica2017.asp

6. Italian Ministry of Health $(\mathrm{MoH})$. Morbillo in Italia, bollettino settimanale. [Measles in Italy: weekly bulletin]. Rome: $\mathrm{MoH}$; [Accessed 29 Aug 2017]. Italian. Available from: http://www. salute.gov.it/portale/news/p3_2_1_1_1.jsp?lingua=italiano\&m enu $=$ notizie $\& p=$ dalministero $\& \overline{i d}=3057$

7. Centers for Disease Control and Prevention (CDC). Travelers' Health. Measles in Italy. Atlanta: CDC; [Accessed 29 Aug 2017]. Available from: https://wwwnc.cdc.gov/travel/notices/watch/ measles-italy 
8. Filia A, Bella A, Rota M, Tavilla A, Magurano F, Baggieri $M$, et al. Analysis of national measles surveillance data in Italy from October 2010 to December 2011 and priorities for reaching the 2015 measles elimination goal. Euro Surveill. 2013;18(20):20480.PMID: 23725868

9. Italian Ministry of Health. Vaccinazioni dell'età pediatrica e dell'adolescente - Coperture vaccinali [Childhood and adolescent vaccinations - Vaccine coverage.]. Rome: Ministry of

Health. [Accessed 13 Sep 2017]. Italian. Available from: http:// www.salute.gov.it/portale/documentazione/p6_2_8_3_1. jsp?id $=20$

10. Veneto Region. Italy. ULSS2o Verona. Indagine sui determinanti del rifiuto dell'offerta vaccinale nella Regione Veneto. [Final report. Survey to identify determinants of vaccine refusal in the Veneto region, Italy]. Verona: Veneto Region Department of Health; [Accessed 13 September 2017]. Italian. Available from: https://prevenzione.ulss2o.verona.it/ docs/RicercheScelteVaccinali/Indagine-Determinanti-SceltaVaccinale-Report.pdf

11. Italian Ministry of Health $(\mathrm{MoH})$. Il Decreto vaccini è legge, tutte le novità. [The vaccination decree is now law, all the novelties introduced English]. Rome: MoH; [Accessed 29 Aug 2017]. Italian. Available from: http://www.salute.gov.it/ portale/news/p3_2_1_1_1.jsp?lingua=italiano\&menu=notizie\& $p=$ dalministero\& $\overline{i d}=3027$

12. European Centre for Disease Prevention and Control (ECDC). Epidemiological update: Measles - monitoring European outbreaks, 7 July 2017. Stockholm: ECDC; [Accessed 31 Aug 2017]. Available from: https://ecdc.europa.eu/en/news-events/ epidemiological-update-measles-monitoring-europeanoutbreaks-7-july-2017

13. European Centre for Disease Prevention and Control (ECDC). Ongoing outbreak of measles in Romania, risk of spread and epidemiological situation in EU/EEA countries- 3 March 2017. Stockholm: ECDC; 7 Mar 2017. Available from: https:// ecdc.europa.eu/sites/portal/files/media/en/publications/ Publications/27-02-2017-RRA-Measles-Romania\%2C\%20 European\%2oUnion\%2ocountries.pdf

14. Filia A, Bella A, Cadeddu G, Milia MR, Del Manso M, Rota MC, et al. Extensive Nosocomial Transmission of Measles Originating in Cruise Ship Passenger, Sardinia, Italy, 2014. Emerg Infect Dis. 2015;21(8):1444-6. DOI: 10.3201/ eid2108.141105 PMID: 26196266

15. Porretta A, Quattrone F, Aquino F, Pieve G, Bruni B, Gemignani G, et al. A nosocomial measles outbreak in Italy, February-April 2017. Euro Surveill. 2017;22(33):30597. DOI: 10.2807/1560-7917.ES.2017.22.33.30597 PMID: 28840827

16. Amendola A, Bianchi S, Frati ER, Ciceri G, Faccini M, Senatore $\mathrm{S}$, et al. Ongoing large measles outbreak with nosocomial transmission in Milan, northern Italy, March-August 2017. Euro Surveill. 2017;22(33):30596. DOI: 10.2807/1560-7917. ES.2017.22.33.30596 PMID: 28840825

17. Grammens T, Schirvel C, Leenen S, Shodu N, Hutse V, Mendes da Costa E, et al. Ongoing measles outbreak in Wallonia, Belgium, December 2016 to March 2017: characteristics and challenges. Euro Surveill. 2017;22(17):30524. DOI: 10.2807/1560-7917.ES.2017.22.17.30524 PMID: 28488998

18. Filia A, Amendola A, Faccini M, Del Manso M, Senatore S, Bianchi S, et al. Outbreak of a new measles B3 variant in the Roma/Sinti population with transmission in the nosocomial setting, Italy, November 2015 to April 2016. Euro Surveill. 2016;21(20):30235. DOI: 10.2807/1560-7917. ES.2016.21.20.30235 PMID: 27240004

19. Kurchatova A, Krumova S, Vladimirova N, Nikolaeva-Glomb L, Stoyanova A, Kantardjiev T, et al. Preliminary findings indicate nosocomial transmission and Roma population as most affected group in ongoing measles B3 genotype outbreak in Bulgaria, March to August 2017. Euro Surveill. 2017;22(36):30611. DOI: 10.2807/1560-7917.ES.2017.22.36.3061

20. Datta SS, O’Connor PM, Jankovic D, Muscat M, Ben Mamou MC, Singh S, et al. Progress and challenges in measles and rubella elimination in the WHO European Region. Vaccine. 2017;S0264-410X(17)30829-0.; Epub ahead of print. DOI: 10.1016/j.vaccine.2017.06.042 PMID: 28651838

\section{License and copyright}

This is an open-access article distributed under the terms of the Creative Commons Attribution (CC BY 4.0) Licence. You may share and adapt the material, but must give appropriate credit to the source, provide a link to the licence, and indicate if changes were made.

This article is copyright of the authors, 2017. 